\title{
Optical Image Reconstruction
}

National Cancer Institute

\section{Source}

National Cancer Institute. Optical Image Reconstruction. NCI Thesaurus. Code C19339.

The process of generating an image from the raw data, or set of unprocessed

measurements, made by an imaging system. (from AmershamHealth Medcyclopaedia) 